\title{
Los mercados públicos: espacios urbanos en disputa ${ }^{1}$ Public markets: Urban spaces in dispute
}

\author{
Adrián Hernández Cordero* \\ Universidad Autónoma Metropolitana Iztapalapa, Ciudad de México, México \\ ORCID: http://orcid.org/o000-0002-5736-I37I \\ DoI: http://dx.doi.org/10.28928/revistaiztapalapa/832017/aot2/hernandezcorderoa
}

\section{Resumen}

El objetivo del artículo es examinar las transformaciones de los mercados públicos y los conflictos involucrados. El análisis se realiza tomando como referencia los mercados La Boqueria y Santa Catalina, ambos en la ciudad de Barcelona. El trabajo se fundamenta en los conceptos: gentrificación, turistificación y conflicto urbano. La metodología combina observaciones y la consulta de información secundaria. Los resultados apuntan a que los mercados estudiados experimentan profundos procesos de cambio a partir de la implementación de politicas públicas neoliberales. En este contexto, surgen tensiones que sitúan en el centro del debate las disputas por la ciudad.

Palabras clave: comercio minorista, consumo, gentrificación, turistificación, Barcelona.

\begin{abstract}
The article aims to examine the transformations of public markets and the conflicts they involve. The analysis is focused on the markets La Boqueria and Santa Catalina, both in the city of Barcelona. The text is based on the concepts of gentrification, touristification and urban conflict. The methodology combines observations and secondary data review. The results suggest that the studied markets are subjects of important processes of change due to the implementation of neoliberal policies. In this context, tensions between different actors and urban struggles become visible as core questions of the debate.
\end{abstract}

Keywords‡ Retail trade, consumption, gentrification, touristification, Barcelona.

1 Para la realización de este trabajo se contó con el financiamiento del Consejo Nacional de Ciencia y Tecnología. Una versión preliminar del documento se presentó en el $V$ Seminario Internacional Ciudad, Comercio y Consumo celebrado en México durante 2015.

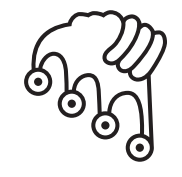

IZTAPALAPA

Agua sobre lajas

*adn2I2@gmail.com 
$L$ os mercados municipales, sobre todo en las ciudades europeas, han tenido un papel fundamental debido a que han articulado el espacio urbano y rural a través del intercambio económico y alimentario (Guàrdia, 20I2). Los mercados como los conocemos en la actualidad datan del siglo xix y son el resultado de las ideas urbanísticas predominantes en ese periodo, las cuales indicaban que las plazas (los espacios destinados al comercio minorista) y los mercadillos tenían que estar resguardados bajo techo. Pintaudi (2006) nos recuerda que en Occidente las ciudades medievales no contaban con un espacio establecido para el intercambio económico de productos básicos. Los mercadillos situados al aire libre fueron tomando mayor relevancia a tal grado que posteriormente los sitios en los que se instalaban dieron origen a mercados techados, como en el caso de La Boqueria en la ciudad de Barcelona. De esta forma, se reforzó la función de los mercados públicos en el capitalismo, que según Pintaudi (2006), consistió en centralizar el comercio en un lugar particular que facilitó el control sobre las mercancías, así como de las fuentes que suministraban productos.

A partir de entonces y con el auge del hierro se comenzaron a construir recintos para arropar a los comerciantes y clientes, como ocurrió en el Reino Unido y Francia. En estos países, según Guàrdia y Oyòn (2007), proliferaron las edificaciones de mercados tomando como referencia Les Halles en Paris. Este fue reconstruido en 1854 debido al estado vetusto en que se encontraba y que se contraponía a las directrices urbanas planteadas por el Barón Haussmann. El nuevo recinto de Les Halles se construyó a partir del hierro y el vidrio, con la finalidad de combinar la magnificiencia con la pulcritud, valores propios de la capital del imperio moderno (Antigüedad, 2015). En este conxtexto, Guàrdia (2012) argumenta que los mercados representaron nuevas construcciones que tenían el objetivo de concentrar y regular en espacios cerrados, cubiertos y organizados, las actividades comerciales que habían invadido desordenadamente las plazas y calles. Por lo anterior, las nuevas edificaciones perseguían el orden urbanístico y la regulación de las funciones comerciales, buscando ofrecer mayores elementos de higiene en su desarrollo. 
El tránsito de la plaza al mercado ocurrió en el contexto de transformaciones urbanas de más amplio alcance -a finales del siglo xix y principios del $\mathrm{xx}$ - como fue la adopción del Plan de Reforma y Ensanche de Barcelona, mejor conocido como el Plan Cerdà, que tenía como finalidad generar la expansión ordenada de la ciudad. El Plan grosso modo se fundó en los criterios racionalistas mediante el establecimiento de una cuadrícula que permitía contar con una adecuada higiene de la ciudad, así como favorecer la circulación mediante grandes avenidas. En el tópico de los mercados, Cerdà planteó construir en el Ensanche un mercado cada 900 metros. Mientras que en el Centro Histórico, que era considerado anacrónico, se pensó demoler el mercado de La Boqueria debido a que se proyectó la construcción de un boulevard en La Rambla. En este marco de expansión urbana y crecimiento demográfico, Robles (2010) sostiene que los mercados tenían la encomienda de concentrar la oferta, facilitar la distribución de alimentos y controlar la calidad e higiene de las mercancías. Además, los centros de abasto ya no se comprendieron unicamente como enclaves de distribución de mercaderías sino que se conviertieron en espacios de control social. Esto es a partir de la regulación de los precios de los productos básicos, con la finalidad de evitar conflictos sociales (Guàrdia, 2012).

Guàrdia, Oyón y Fava (2015) revelan que el auge de la construcción de mercados en las principales ciudades europeas se detuvo en los albores del siglo $\mathrm{xx}$, pero sobre todo en la posguerra debido a la falta de recursos económicos para seguir construyendo equipamiento de este tipo, o bien, para mantener los existentes. Mientras que en España, contrariamente a la tendencia, fue el periodo de apogeo en la construcción de mercados (Fava, Guàrdia y Oyón, 2009). Destaca el caso de Barcelona: entre I950 y 1979 se erigieron cerca de una veintena de mercados (que representan $50 \%$ del total actual), sobre todo en barrios que no contaban con este tipo de infraestructura. Resalta la influencia de los postulados de Cerdá en la planeación urbana de la capital catalana, debido a que él argumentó que cada vecino contara con un centro de abasto a menos de un kilómetro de distancia de su residencia.

A partir de las últimas décadas del siglo pasado los mercados municipales se enfrentan a una importante serie de desafíos por diversos factores: las trasformaciones en la estructura urbanística y demográfica de la ciudad, el cambio en las pautas de consumo, así como la competencia de formas de distribución y comercio lideradas por los supermercados. La introducción de los hipermercados en la segunda mitad del siglo pasado es propia del modelo urbano desarrollista que se promovió en las ciudades europeas y que se caracterizó por la suburbanización, los conjuntos residenciales de baja densidad, la construcción de autovías y el triunfo del automóvil como mecanismo de la movilidad urbana. Ello ocasionó, según López (2002; 2007), 
un divorcio entre el espacio público y el comercio a partir de la individualización y privatización de las formas de consumo. Las políticas públicas urbanas enfocadas hacia el crecimiento de la periferia, así como la salida de las clases medias de las zonas centrales influenciadas por imaginarios suburbanos provocaron que los centros de las ciudades y sus mercados experimentaran un proceso de desinversión y pérdida de valor simbólico. El centro de la ciudad y su forma de comercio tradicional y minorista entraron en crisis.

No es hasta las últimas décadas del siglo pasado que los mercados municipales son redescubiertos por el sector gubernamental, debido al regreso a la ciudad construida (Díaz, 2013). Distintos autores como Ogden y Schnoebelen (2005), Ogden y Hall (2004) han estudiado ciudades europeas como París, Londres y Boloña y coinciden en señalar que en los últimos años se presenta un incremento de los flujos migratorios hacia las zonas centrales de la metrópolis. Este movimiento se enmarca en la denominada segunda transición demográfica, ${ }^{2}$ que implica procesos de reurbanización por parte de población joven de clase media y con géneros de vida cosmopolitas. De esta manera, se compensan los fenómenos de envejecimiento y mortalidad que experimentan los centros urbanos e influyen en sus procesos de gentrificación. En este contexto, los mercados adquieren una importancia fundamental por su potencial económico y estratégico en las nuevas dinámicas urbanas. Por esta razón no resulta extraño, como señalan González y Waley (2012), que a los gobiernos locales y al sector empresarial les urgiera intervenir en los centros de abasto para su rescate comercial y urbanístico.

En los últimos años, sobre todo a partir del estudio de ciudades europeas, se comienza a hablar de gentrificación comercial, es decir, de la forma en la que el comercio minorista y tradicional es sustituido por tipologías mercantiles dirigidas hacia un sector de ingresos económicos medios y altos. Varios autores (Boldrini y Malizia, 2013; Hernández, 2014) han demostrado que los mercados municipales desempeñan un papel fundamental como impulsores de estas dinámicas. Cabe mencionar que la gentrificación de los centros de abasto no solo implica una cuestión material sino también simbólica. La narrativa que justifica su renovación se acompaña de imaginarios urbanos vinculados a estilos de vida que buscan aproximarse a lo antiguo y auténtico mediante hábitos de consumo que, como señala Bourdieu (1989), funcionan como dispositivos de distinción. De esta forma, la gentrificación de los

2 Sus características son la disminución y el retardo de la fertilidad, la postergación del matrimonio, el aumento de la cohabitación, el incremento de divorcios y el crecimiento de las familias monoparentales. 
mercados, al igual que en el siglo xix, es una cuestión de higiene. Por lo que los organismos públicos y privados se enfocan en extirpar los males urbanos (suciedad y pobreza) de los añejos centros de abasto popular. La finalidad es garantizar que las nuevas clases medias tengan experiencias de consumo seguras, limpias y saludables, aunque supongan efectos excluyentes hacia los menos favorecidos.

En este contexto, se plantea estudiar las transformaciones que están experimentado los principales mercados del Centro Histórico de Barcelona, ${ }^{3}$ en el marco del profundo proceso de reconfiguración socioterritorial que vive la capital catalana. Este ha implicado un importante número de intervenciones urbanísticas que han sido documentadas por varios autores (López, 1986; Subirats y Rius, 2008; Tapada y Arbaci, 20II) desde diversos enfoques. A pesar de las importantes contribuciones se han dejado de lado una serie de reflexiones vinculadas con la infraestructura comercial de proximidad, es decir, los mercados y su papel en la renovación urbana. Justamente es en esa dirección que el presente documento busca abonar una serie de argumentos que pueden contribuir a la discusión académica.

Los mercados analizados fueron elegidos por su relevancia simbólica y funcional en el ámbito de Barcelona. Ambos equipamientos se localizan en el Centro Histórico pero en diferentes barrios: San José o La Boqueria en el Raval y Santa Catalina en La Ribera. Además de su ubicación se tomó en cuenta su historia más o menos compartida. La Boqueria fue inaugurado en 1840 siguiendo el proyecto del arquitecto Josep Mas i Vila. Él, junto con Josep Buxareu, también esbozó el mercado de Santa Catalina, que fue abierto en I848. Ambos fueron diseñados y construidos tomando como referencia los parámetros edilicios de los mercados franceses (Guàrdia, Fava y Oyòn, 20Io). Hacia finales del siglo xix y comienzos del xx estos centros de abasto fueron de amplia relevancia para el comercio y la distribución de alimentos de la ciudad. Varias décadas después han vivido, junto a los barrios en los que se ubican, transformaciones más o menos paralelas a partir de las políticas públicas de reforma urbana que se adoptaron en el marco de la organización de los Juegos Olímpicos en Barcelona. El mercado de La Boqueria y Santa Catalina se han vuelto paradigmáticos, debido a que son los prototipos en los que el ayuntamiento de la ciudad ha ensayado su progresiva reconversión para impulsar procesos de turistificación (La Boqueria) y de gentrificación (Santa Catalina). La experiencia de estos

3 El Centro Histórico de Barcelona en catalán se denomina Ciutat Vella. Se compone de los barrios de Barceloneta, La Ribera o el Casc Antic, Gòtic y Raval. Tiene una extensión de $4.49 \mathrm{~km}^{2}$ y una población de cerca de 105000 habitantes. 
ha trascendido la escala local y nacional, puesto que su influencia se ha expandido a nivel internacional como se verá más adelante.

El presente artículo se desarrolló entre la primavera de 2013 y el verano de 2015 en la ciudad de Barcelona. Entre las técnicas de investigación utilizadas está la observación en ambos mercados, la cual se llevó a cabo en diferentes días y horarios. Asimismo, se realizó un amplió trabajo de gabinete en los archivos del Instituto Municipal de Mercados, en la Biblioteca de Urbanismo del Ayuntamiento de Barcelona y en la Biblioteca Nacional de Cataluña. Además, se efectuó un seguimiento hemerográfico sobre los casos analizados.

\section{Barcelona y el "Modelo de mercados"4}

Hasta los años setenta del siglo pasado los mercados en Barcelona mantenían un importante papel de abastecimiento de productos alimentarios frescos, debido en gran parte a la política proteccionista y a las malas condiciones socioeconómicas de la dictadura franquista (Guàrdia, 20I2). Ello ocasionó que los supermercados en España se instalaran más tarde que en otros países europeos (Juste, 1993), por lo que indirectamente se reforzó el papel de los mercados como centros de abasto popular. Sin embargo, a partir del restablecimiento de la democracia y con la llegada del nuevo ayuntamiento de Barcelona comenzaron una serie de cambios sustanciales en el desarrollo urbano y en la gestión de la ciudad. Algunos académicos (Albet y Garcia, 2014; Delgado, 2007; Montaner, 2012a) nombraron esta serie de intervenciones como el Modelo Barcelona, que también implicó una ruptura en la política de los mercados municipales.

No es tema de este trabajo examinar el Modelo Barcelona, el cual ha sido ampliamente analizado desde diversas perspectivas. Por ejemplo, Borja (1995), en una primera etapa, fue uno de sus principales impulsores, a partir de la promoción de las políticas públicas aplicadas por el ayuntamiento de Barcelona durante la consolidación del regimen democrático en España. Mientras que autores como Capel (2005) muestran los efectos negativos -incremento del valor de suelo, carencia de planes de vivienda social, fenómenos de exclusión social, por mencionar algunosque han implicado las actuaciones urbanas en su maridaje con el capital privado. A medio camino se ubican estudios como el de García (2008), quien sopesa los apor-

4 El Modelo de mercado Barcelona es una expresión utilizada por las autoridades gubernamentales y en el presente documento no se discutirá la pertinencia del uso conceptual de "modelo". 
tes del modelo en relación con los posibles riesgos del incremento de la brecha de desigualdad y cohesión social. Existe consenso en el impacto que tuvo la actuación gubernamental sobre la ciudad, la cual marcó un parteaguas para Barcelona. En este sentido, el Modelo Barcelona se caracterizó por tener efectos diferenciados sobre la ciudad. En los sectores periféricos se trabajó en la dignificación de los barrios con un alto rezago social, teniendo efectos en el aumento de la calidad de vida. Sin embargo, en las zonas estratégicas y de un alto potencial económico, como el Centro Histórico o el frente marítimo, las operaciones han implicado graves consecuencias socioespaciales para los residentes.

A mediados de los años ochenta se promulgó el instrumento de planeación que sentó las bases de la intervención en los mercados municipales en Barcelona: el Plan Especial de Equipamiento Comercial Alimentario. Cabruja (1992) señala que este buscaba que los mercados municipales actuaran como nodos articuladores de la trama urbana. La nueva visión sobre los mercados, según Guàrdia (2012), generó un cambio fundamental porque se abandonó su función tradicional de asegurar el aprovisionamiento a un precio accesible para las clases populares. Desde ese momento se entendieron como equipamientos que deberían transformarse en un sector comercial dinámico, moderno, equilibrado. Se convirtieron en motores de desarrollo urbano capitalista cuya finalidad consistía en impulsar operaciones urbanísticas y comerciales en sus entornos próximos y, por ende, en la ciudad. Así, se inauguró una nueva etapa en el escenario urbano de Barcelona que posteriormente sería replicada en otras latitudes.

En el marco de la celebración de los Juegos Olímpicos de 1992, que marca un hito en la trasformación socioespacial de la capital catalana, se creó el Instituto Municipal de Mercados de Barcelona. Organismo autónomo que gestiona los centros de abasto y que ha llevado a cabo la remodelación de 19 mercados de la ciudad, cifra que representa $48 \%$ del total.

Desde la nueva institución se instrumentaron una serie de medidas que buscaron la modernización de los mercados públicos a través de:

- La remodelación arquitectónica del edificio y, en su caso, la recuperación del valor patrimonial. Incluso, la reconstrucción con elementos de la arquitectura espectáculo.

- El rediseño de los comercios para que fueran sostenibles económicamente. Se llevó a cabo la reducción de la superficie comercial de las paradas, el surgimiento de tipologías de comercios de degustación, así como la instalación de bares, restaurantes y supermercados. 
- La profesionalización de los comerciantes en la búsqueda de eficiencia empresarial. Se ampliaron los horarios de atención y se incorporaron las nuevas tecnologías de la información. Asimismo, se enfocó la oferta de productos cada vez más hacia lo gourmet, artesanal y ecológico.

- La adopción de un modelo de financiación mixta. El ayuntamiento otorgó 50 \% de la inversión, mientras que el resto se obtuvo por medio de las concesiones entregadas a empresas de supermercados y/o restaurantes para que se instalaran dentro de los equipamientos públicos.

- La promoción de los mercados a través de campañas publicitarias, así como la organización de eventos de diversa índole (sobre todo culturales), con la finalidad de captar una mayor clientela.

El modelo de gestión otorga mayor injerencia a la iniciativa privada en los mercados públicos, con el objetivo de hacerlos más competitivos mediante lo que el Instituto considera la actualización de la oferta comercial y la adaptación a su entorno. La administración pública justificó a través de la narrativa del deterioro físico y comercial la actuación en los centros de abasto, la cual sin duda fue producto de la propia desinversión gubernamental. De esta manera, se aprovechan estos viejos equipamientos por las oportunidades de maximización financiera que ofrecen, sobre todo en zonas turísticas y de alto valor económico como es el Centro Histórico, los barrios con algún tipo de patrimonio y la zona costera.

La experiencia de la capital catalana ha sido reconocida en España y a nivel global. En 2015 la ciudad de Barcelona organizó el Congreso Internacional de Mercados Públicos para exhibir el modelo de mercados local como referente internacional a los asistentes de más de 120 ciudades del mundo. En ese marco, Barcelona recibió el premio Ciudad Mercado, debido a que los organizadores consideraron que representaba un modelo en la defensa de sus mercados, así como en su utilización como herramienta de desarrollo urbano sostenible. Siguiendo a Montaner (20I2b) se puede decir que es una muestra de cómo Barcelona dejó de ser un modelo para convertirse en una marca registrada. Una rúbrica que los políticos y algunos urbanistas catalanes vanagloriados en Latinoamérica han sabido vender muy bien, pero que oculta efectos como el desplazamiento y la exclusión social que pueden generar las revitalizaciones urbanas.

El liderazgo de Barcelona en este rubro es tan potente que encabeza dos proyectos sobre mercados en Europa: URBACT Markets (financiado por la Unión Europea y en el cual participan io países europeos), así como EMPORIon Med (que agrupa cinco ciudades mediterráneas). La finalidad de ambos programas se basó en compartir 
y replicar las prácticas de Barcelona respecto de los mercados municipales como motores para promover el empleo y el emprendimiento, la regeneración urbana y la sostenibilidad. Cabría señalar que esta serie de términos provienen de lo que Harvey (1989) denomina el empresarialismo urbano, que es utilizado por los gobiernos para incentivar la mercantilización de la ciudad beneficiando a los poderes financieros y excluyendo a los menos favorecidos.

\section{Los nuevos usos de los mercados: entre la gentrificación y la turisitificación}

El redescubrimiento de los mercados públicos es fundamental para el actual contexto urbano que está marcado por la narrativa de la competitividad global. Con la tendencia que impera en las urbes occidentales de volver a sus áreas centrales, los mercados públicos son vistos como viejas infraestructuras localizadas en zonas estratégicas de la ciudad. Ante el discurso del estado de deterioro en el que se encuentran, estos emergen como espacios de oportunidad para promover operaciones urbanísticas y económicas por medio de dos fenómenos: la turisitificación y la gentrificación. Ambas tendencias se analizan a partir de los mercados: San José, mejor conocido como La Boqueria, y Santa Catalina; ambos en el Centro Histórico de Barcelona.

\section{La turistificación del mercado de La Boqueria}

En los últimos años la actividad turística ha cobrado mayor relevancia en Barcelona. A partir de la organización de los Juegos Olímpicos de 1992 la ciudad se posicionó como un destino turístico a nivel internacional. Solo hay que mirar las cifras del Consorcio Turisme de Barcelona, que señala cómo en 20 años (1993 a 2013) Barcelona multiplicó por tres el número de pernoctantes y albergó en total a Ioo millones de turistas. El crecimiento de esa actividad en la capital catalana ha tenido impactos en la modificación del mercado del suelo y en el incremento de su valor. También ha implicado cambios en la estructura comercial y la llegada cada vez más constante de personas de diversas latitudes que deciden residir en la ciudad.

Los mercados de Barcelona se han visto inmersos en esta dinámica, sobre todo a partir de las políticas públicas de fomento a la actividad turística que se vienen impulsando desde la Generalidad de Cataluña y el Ayuntamiento de Barcelona. Los mercados municipales han sido entendidos como potentes espacios de impulso turístico para la capital catalana. 
El mercado de La Boqueria es el máximo ejemplo de la conversión de un centro de abasto en un ícono turístico. Incluso esa trasformación ha sido reconocida a nivel internacional y La Boqueria fue considerada como el mejor mercado del mundo según el Congreso Mundial de Mercados efectuado en 2005. Sobre todo se valoró que se ajusta a las políticas globales impulsadas por organismos supranacionales como el Banco Interamericano de Desarrollo (2007), el cual considera a los mercados como detonadores de desarrollo económico de las ciudades.

En la actualidad, La Boqueria es uno de los mercados más famosos del orbe justamente por su difusión turística. El mercado cuenta con una ubicación privilegiada, ya que se encuentra a un costado del famoso paseo de la Rambla que se ha convertido en el eje del tránsito de turistas en la ciudad. Según la Asociación de Amigos, Vecinos y Comerciantes de la Rambla por ella transitan aproximadamente 78 millones de visitantes anuales, esto es, cerca de 213000 personas diariamente, de los cuales casi $70 \%$ pueden considerarse turistas (españoles y extranjeros). Este importante flujo de personas que circulan por la Rambla ha resultado trascendental para que La Boqueria haya experimentado el crecimiento de visitantes, sobre todo por su valor histórico y patrimonial material (estructura arquitectónica) e inmaterial (los productos y alimentos) que lo convierte en un referente turístico de la ciudad.

El Ayuntamiento de Barcelona, consciente de la importancia de La Boqueria, comenzó en 1998 su remodelación que entre otras cosas implicó su ampliación, la construcción de oficinas y un restaurante. Además, se suprimió casi una centena de establecimientos que se instalaban en los porches y columnas de la plaza exterior, con la finalidad de que recobrara su aspecto original y así su arquitectura fuera apreciada por los visitantes. En el sitio de los antiguos locales se instalarían progresivamente bares de degustación y restaurantes, evidenciando que el mercado tendía a cambiar su actividad de centro de abasto a espacio de ocio, recreación y consumo turístico.

Hasta la década de los noventa La Boqueria se caracterizó por ofrecer una amplia variedad de alimentos a precios relativamente accesibles, lo cual lo había posicionado como el centro de provisión más destacado de la ciudad. Además, contaba con bares que ofrecían una gastronomía popular. Esta combinación de productos llevó a que el mercado fuera ampliamente reconocido en las prácticas cotidianas de los habitantes del centro de Barcelona. Incluso fue denominado por el escritor barcelonés Vázquez Montalbán (2013) como la Catedral de los sentidos, en la que convergían marchantes y sibaritas. La figura del templo ha sido ampliamente explotada desde la perspectiva turística, debido a que la sacralidad ha llevado a que La Boqueria sea considerada un templo gourmet. Delgado (2014) señala que los mercados se vuelven grandes barras de pinchos, cervezas artesanales y postres en donde sectores de clase 
media acuden a venerar, observar y probar objetos que, aunque comestibles, son igualmente museificados. Los mercados se asumen como un nuevo tipo de museo donde, a diferencia de los recintos tradicionales, el turista es capaz de presenciar $y$ participar en la escenificación de la vida cotidiana de la ciudad, además de ofrecer un festín de posibilidades sensoriales, ya que en el mercado es posible tocar, oler y probar.

En los últimos años, a partir del importante incremento de turistas, La Boqueria ha vivido una trasformación en los patrones de consumo y, por lo tanto, en su oferta comercial debido a que en términos cuantitativos los turistas son los principales consumidores físicos y simbólicos. Aunque no se puede dejar de señalar que hay una importante presencia de vecinos del Centro Histórico, por lo que aún se mezclan las pescaderías, carnicerías y otros puestos típicos con los nuevos establecimientos que ofrecen golosinas, chocolates, souvenirs y alimentos tipo fast food como trozos de pizzas, conos de virutas de jamón, woks y canastillas coloridas de trozos de frutas que están dirigidas a satisfacer la demanda turística. De esta forma, se genera una polarización en la oferta, ya que este tipo de alimentos responde al modelo turístico de masas que se contrapone al slow food preferido por los visitantes sibaritas y gourmets, evidenciando que La Boqueria alberga un conflicto entre lo auténtico y lo banal que se entrecruza con una cuestión de clases sociales y preferencias de consumo.

\section{La gentrificación del mercado de Santa Catalina}

El mercado de Santa Catalina se ubica en el barrio de La Ribera y se erigió como uno de los principales centros de abasto de la ciudad. A partir de mediados de la centuria pasada atravesó un proceso de desinversión, el cual fue resultado de la propia política de inacción gubernamental en el Centro Histórico de Barcelona. En los años ochenta, en el contexto de la transición a la democracia y con la efervescencia de los movimientos ciudadanos, los habitantes del vecindario promovieron su reconstrucción a través de un instrumento de planeación participativa denominado Plan Popular. ${ }^{5}$ Esta idea fue recogida en el Plan Especial de Reforma Interior de 1986 que promulgó el Ayuntamiento de Barcelona. Sin embargo, la remodelación no comenzó a ejecutarse hasta el 1999, aunque sin tener en consideración las propuestas vecinales de mantenerlo como un equipamiento público para el vecindario.

5 El Plan Popular surgió como contraparte de los PERI. Los Planes de Reforma Interior son instrumentos de planeación que contemplaba el Plan General Metropolitano de Barcelona de 1976 y que permitían modificar los lineamientos generales de planeación de un polígono o barrio a través de planes a detalle. 
En las nuevas directrices gubernamentales se planteó enfocar el mercado hacia la trasformación socioespacial de su entorno, así como a la actividad turística. ${ }^{6}$

Las obras del mercado de Santa Catalina afectaron a los habitantes y locatarios, debido a que el equipamiento fue cerrado y emplazado temporalmente en carpas provisionales fuera del barrio; esa situación se prolongó por seis años debido al hallazgo de restos arqueológicos en el subsuelo. La demora en las obras ocasionó efectos fatídicos para el Casco Antiguo en términos económicos. Según Medina y Álvarez (2009) cerca de 200 tiendas cercanas al mercado cerraron. La prolongación de las obras influyó en la desaparición del centro articulador de la vida barrial, debido a que el mercado, además de su función como sitio de reproducción de la vida cotidiana, funcionaba como un espacio público. ${ }^{7}$

El nuevo proyecto de reconstrucción de Santa Catalina incluyó una ostentosa techumbre a cargo del connotado arquitecto Enric Miralles. El mercado se instituyó como el prototipo del Modelo de Mercados Barcelona que impulsó el Instituto Municipal de Mercados, según el cual se realizó la reducción del número de locales bajo la siguiente justificación: "Una racionalización de los negocios que, por un lado, reducía la cantidad, pero por otro, ganaban en dimensiones, profesionalidad y competitividad" (2012:34). Desde una narrativa neoliberal se buscaba una supuesta eficiencia que se veía obstaculizada por los establecimientos antiguos. Las paradas pasaron de 100 a 68, teniendo como objetivo liberar suelo para que se instalara un restaurante de medio standing, así como un supermercado en el sótano. Ambas instalaciones fueron admitidas como mecanismos para cubrir la financiación de las obras de reconstrucción del equipamiento, sin importar que existiera una competencia desequilibrada hacia los locatarios.

La intervención en el mercado de Santa Catalina hace evidente una nueva concepción de los mercados municipales en Barcelona. El Ayuntamiento, sin renunciar a sus titularidades públicas, fomenta un proceso de semiprivatización de éstos.

El mercado de Santa Catalina, desde su reapertura en 2005, ofrece una nueva fisonomía debido a que prácticamente fue reconstruido. Solo se mantuvo su fachada,

6 Jordi Portabella, entonces segundo teniente de alcalde y responsable del área de Comercio y Turismo del Ayuntamiento, declaró a El País que el mercado sería "un eje de una nueva ruta que redistribuiría el turismo de la ciudad”. Asimismo, Miralles y Tagliabue (2005) en el proyecto ejecutivo argumentaban que el mercado formaría parte de un recorrido histórico y cultural que conectaría el famoso Templo de Santa María del Mar con la Catedral de Barcelona a través de la calle Montcada (donde se ubica el famoso Museo Picasso).

7 Se entiende a los mercados como espacios públicos no formales, es decir, normativamente no lo son pero las interacciones sociales que allí se generan instituyen emplazamientos abiertos, dinámicos e incluyentes. 
la cual es coronada por el techo ondulado y multicolor. Además, dentro del recinto se abrió una zona en la que se puede apreciar parte de los restos arqueológicos hallados, contribuyendo a su museificación. Los turistas que visitan el centro de Barcelona y los nuevos habitantes del barrio, que han llegado a partir del proceso de gentrificación, tienen a su disposición un híbrido espacio comercial en el que se mezclan recursos históricos con una prótesis de arquitectura espectáculo que enmarcan la experiencia de consumo. La nueva oferta del mercado de Santa Catalina se caracteriza por poner a la venta además de los productos alimentarios básicos, artículos de tipo gourmet y orgánicos dirigidos a los sectores de clase media instalados en el Casco Antiguo.

\section{Los mercados públicos‡ espacios de conflictos}

Las transformaciones que han experimentado los mercados municipales estudiados no han estado alejadas de problemáticas y conflictos. A continuación se presentan las disputas que han tenido lugar entre diversos actores sociales en los mercados de La Boqueria y Santa Catalina.

\section{El mercado de La Boqueria}

Los conflictos por la turistificación de La Boqueria son relativamente recientes y se vinculan con eventos coyunturales como fue la reactivación de la Red Vecinal del Centro Histórico ${ }^{8}$ que aglutina a las principales asociaciones de residentes de éste. Cabe mencionar que la Red estuvo inactiva durante varios años, pero fue durante el primer semestre de 2013 cuando se volvió a reavivar. El motivo fue la decisión adoptada por el entonces Ayuntamiento de Barcelona de modificar el Plan de Usos del Distrito que, entre otras cosas, terminaba con la moratoria dictada en 2010 respecto de la instalación de hoteles y restaurantes en el centro de la ciudad. Igualmente, influyeron las potentes protestas de los vecinos del barrio de la Barceloneta contra los apartamentos turísticos y la presión turística durante el verano de 20I4. Todo ello se sumó a un descontento generalizado en la ciudad contra la masificación turística que provocó sentimientos de despojo en sus habitantes. De esta manera, el turismo se volvió un problema social para varios sectores (sociedad organizada y algunos académicos) debido a su incremento, que implicaba paradójicamente la tematiza- 
ción. A partir de entonces se ha generado una importante reflexión en torno a los efectos de la actividad turística en la ciudad por parte de los residentes organizados.

En este contexto, durante los primeros meses de 2015 algunos moradores de los barrios del Centro Histórico llevaron a cabo una incursión colectiva en La Boqueria para reivindicarlo como un espacio para los barceloneses. Consideraban que les resultaba cada vez más complicado realizar las compras cotidianas por la numerosa presencia de turistas, así como por el cambio en la tipología de comercio que progresivamente tendió a satisfacer la demanda de visitantes. Un sábado, que es el día tradicional en que las personas en Cataluña suelen ir de compras al mercado, se reunieron una media centena de vecinos del Centro Histórico para irrumpir de forma festiva y disputar a los turistas el espacio del que los habitantes se sienten desplazados. Con carteles, equipo de sonido móvil y carritos de compra los vecinos se fueron abriendo paso entre los estrechos pasillos del mercado para recuperarlo, al menos por un par de horas.

La protesta generó diversas reacciones entre los comerciantes, evidenciando las disputas que existen entre ellos. Los comercios tradicionales (carnicerías, pescaderías, fruterías, etc.) simpatizaban con la protesta. Mientras que aquellos dedicados a satisfacer al sector turístico (establecimientos de degustación, comida rápida, souvenirs) se mostraban en contra. Ello muestra la forma en que el sector comercial también está confrontado. La caravana vecinal durante su protesta otorgó reconocimientos a los comercios que aún ofrecen productos básicos para los vecinos, generando empatía entre ambos sectores que buscan defender la actividad comercial de proximidad del mercado municipal.

Unos días después, a pesar de sus diferencias, los comerciantes lograron ponerse de acuerdo en lo que consideraban la saturación de visitantes de La Boqueria. La Asociación de Comerciantes solicitó al Instituto Municipal de Mercados que ejecutara medidas para regular el acceso a turistas, pues consideraban que los 45000 visitantes diarios resultaban insostenibles. El Ayuntamiento de Barcelona no atendió la preocupación, argumentando que resultaba inviable poder regular el acceso al equipamiento y enfatizando que el turismo generaba una importante fuente de ingresos económicos para la ciudad.

Después de una segunda protesta vecinal y en un escenario político adverso para el partido en el poder, ${ }^{9}$ la petición de los comerciantes fue atendida por el Ayuntamiento. En plena campaña electoral, el Consistorio anunció que limitaba el acceso a La Boqueria a grupos organizados de visitantes de 15 o más personas los

9 Entonces gobernaba Convergencia y Unión, partido nacionalista de centro-derecha. 
viernes y sábados, desde la apertura del mercado hasta las 15:00 horas. Esta medida sirvió para contener la presión social de los vecinos y de los locatarios, aunque generó malestar en los promotores turísticos que se sintieron afectados. La restricción de la entrada a grupos al mercado se diluyó paulatinamente y no resolvió de ningún modo el conflicto entre vecinos y turistas; entre comerciantes y comerciantes; $y$ entre vecinos y comerciantes vs. el Ayuntamiento. Se puso de manifiesto que la actividad turística emergía como una preocupación en la que el mercado de La Boqueria solo es un caso paradigmático y que la gestión del turismo está vinculada con el modelo de ciudad imperante, así como con nuevas formas de habitar efímeras (Hiernaux, 20I2) como las de los turistas que contrastan con las de los moradores.

\section{El mercado de Santa Catalina}

En 1999, cuando se dio a conocer la reforma del mercado de Santa Catalina por el Ayuntamiento de Barcelona, la Asociación de Vecinos del Casco Antiguo manifestó su desacuerdo con el proyecto. Sus reivindicaciones se fundamentaban en tres argumentos. Por un lado, desaprobaban la acción gubernamental porque consideraban que no respondía a las demandas históricas vecinales de los años setenta, que solicitaban un equipamiento público para el barrio. Creían que el nuevo mercado no estaba pensado para beneficiar al vecindario sino para fomentar el turismo. Por otro lado, defendían la esencia del mercado como un centro de abasto popular, así como al pequeño comercio de proximidad en el que estaban acostumbrados a realizar sus compras de alimentos básicos. Asimismo, criticaban la instalación de una tienda de supermercado al interior del mercado porque entendían que se estaba llevando a cabo un proceso de privatización del equipamiento municipal.

En cambio, los comerciantes del mercado Santa Catalina apoyaron el proyecto gubernamental considerando que serían beneficiados en sus ventas por la remodelación del recinto, a pesar de que se reduciría la superficie comercial. Por esta razón, tanto la Asociación de Comerciantes como la Asociación de Vecinos tuvieron confrontaciones, mostrando la forma en que una intervención urbana puede generar diferentes opiniones en distintos actores sociales. A pesar del apoyo de los locatarios a la reconstrucción del mercado de Santa Catalina existieron momentos de tensión, debido a que estos se movilizaron para negociar con el Ayuntamiento los altos montos que debían pagar por las reformas. Después de una serie de negociaciones se logró reducir la cantidad solicitada. De esta manera, los comerciantes se posicionaron como un colectivo fundamental para legitimar e impulsar los trabajos 
urbanísticos en el mercado. Respaldaron al Ayuntamiento de manera pública, buscando contrarrestar las críticas existentes por parte de los vecinos.

El mercado de Santa Catalina se volvió un espacio de choque entre el Ayuntamiento y la Asociación de Comerciantes vs. la Asociación de Vecinos. Se confrontaron dos formas de entender la ciudad, su uso y disfrute. Por un lado, aquella que impera en los últimos años que busca recuperar el centro de la ciudad para revalorizarlo. Por otro, los vecinos que pugnaban no solo por el mercado como equipamiento accesible, sino porque entendían que de esta lucha dependía en gran medida su permanencia en el barrio, puesto que a largo plazo las transformaciones que se avecinaban podrían implicar su desplazamiento. En general, existe una sensación de despojo ${ }^{10}$ por parte de los vecinos que aún residen en La Ribera, debido a que no cuentan con suficientes ingresos para adquirir sus alimentos en los nuevos establecimientos del mercado, ni se identifican con su oferta comercial, y adquieren sus víveres en las nuevas fruterías del barrio (regenteadas por población no comunitaria) y en los supermercados. En consecuencia, al menos el mercado de Santa Catalina se ha vuelto un espacio excluyente en función de los ingresos económicos y ha perdido su esencia de espacio público.

Los actuales clientes del mercado de Santa Catalina son los nuevos habitantes que han llegado a La Ribera, quienes valoran contar en su barrio con un mercado de gran valor patrimonial y arquitectónico en el que se pueden hacer las compras cotidianas. Estos habitantes, que generalmente huyeron de la banal periferia buscando el centro de la ciudad como un enclave identitario, pueden recrear ahí, como señala Pintaudi (2006), un espacio tradicional en el que igualmente simulan comportarse de forma tradicional. El mercado de Santa Catalina se volvió un simulacro de la vida barrial con la que alguna vez contó, pero con la garantía de ofrecer una experiencia segura e higiénica. En un escenario controlado las clases medias de habitantes y turistas pueden adquirir productos naturales, frescos e incluso exóticos que se veneran en el cosmopolitismo.

\section{Conclusiones}

Los mercados públicos tienen una gran relevancia en la ciudad, debido a su función de intercambio económico, así como a la posibilidad de articulación de relaciones

10 Hernández Cordero (2016) presenta los resultados de entrevistas que se realizaron a los vecinos de La Ribera respecto del mercado de Santa Catalina. 
sociales. Sus transformaciones muestran las etapas de transición del espacio urbano. Durante la segunda mitad del siglo xIx fueron organizados y cubiertos bajo estructuras de hierro, mostrando que en esa época imperaba la idea de regular la actividad comercial, así como de hacerla higiénica. Un siglo después, con la expansión de la periferia urbana y la desinversión en los centros de las ciudades, se generó un proceso de decadencia en estos y en los mercados públicos, situación que se complejizó con la introducción de nuevas formas de consumo propias del capitalismo desarrollista como los supermercados. A partir de las últimas décadas los centros de abasto son redescubiertos en el contexto del proceso de reurbanización que experimentan las ciudades, volviéndose equipamientos altamente capitalizables en la era neoliberal.

Barcelona resulta un buen ejemplo en la reconversión de sus mercados públicos, sobre todo de aquellos que se ubican en zonas de alta rentabilidad económica como el Centro Histórico y los barrios turísticos. La apuesta del Ayuntamiento de Barcelona ha consistido en dotar de nuevos usos a los viejos equipamientos alimentarios. Por un lado, el mercado de La Boqueria es la más clara muestra del impulso de las políticas turísticas que se ha desarrollado en los últimos años. El mercado es uno de los principales atractivos de la capital catalana; su localización céntrica permite que sea más visitado por turistas que por los propios vecinos. Ello ha implicado la progresiva trasformación de los locales tradicionales, que han dejado de ofrecer alimentos y en su lugar venden productos gastronómicos. Por otro lado, a pesar de que el mercado de Santa Catalina también se pensó como un icono turístico, su propia dinámica ha devenido en un mercado gentrificado. Progresivamente se destina una mayor superficie comercial a mostradores de degustación, así como a la oferta de productos artesanales, ecológicos y gourmets que tienen costos superiores a las mercaderías comunes. Sus principales clientes son los vecinos recién llegados a La Ribera a partir del proceso de renovación urbanística que experimenta la zona en los últimos años. En ambos casos, los mercados dejaron de cumplir su papel principal de equipamientos públicos que brindan alimentos a precios accesibles a los residentes de la ciudad. Se han conformado como espacios excluyentes, dirigidos a satisfacer las demandas de distinción de turistas y habitantes de clase media, que en palabras de Judd (2003) cada vez tienen más similitudes en las prácticas de consumo, así como en las formas de habitar la urbe.

La experiencia de la capital catalana respecto de la reforma de sus mercados municipales ha sido paradigmática. Por ello se justifica su estudio. Diversos autores (Delgadillo, 20I6; González y Waley, 20I2; Hernández y Andreeva; 20I6) han demostrado cómo los mercados estudiados se han vuelto referentes exitosos a escala internacional, por lo que se han asumido como casos dignos de replicar por parte 
de gobiernos y la iniciativa privada en diversas latitudes como Leeds, Madrid y la Ciudad de México.

Los diversos actores involucrados (Ayuntamiento, agentes económicos, comerciantes, vecinos y turistas) en gestionar y practicar los mercados están inmersos en un entramado de relaciones tensas y conflictivas por el uso y disfrute de estos. El escenario es complejo debido a la existencia de opiniones encontradas derivadas de motivaciones económicas, emocionales y políticas. Los mercados se erigen como espacios de lucha de clases, en los que se enfrentan, como diría Hiernaux (2012), grupos populares para los cuales la vida en el mercado es parte de mecanismos de supervivencia, mientras que los nuevos habitantes y practicantes promueven intereses relacionados con su calidad de vida. Por lo tanto, chocan estos proyectos políticos que entienden a la ciudad de forma desigual. Por un lado, están aquellos sectores (gobierno y asociaciones de comerciantes) que los visualizan como motores de transformación social a través de importantes operaciones urbanísticas, así como centros de consumo de clases medias, aunque ello implique la tematización de la ciudad. Por otro, están los colectivos vecinales que pugnan por que los mercados sean renovados de forma no excluyente, es decir, que mantengan su carácter popular mediante su esencia pública.

La trasformación de los mercados por fenómenos como la gentrificación y el turismo generan que estos pierdan el sentido de espacio público que se constituye a través de relaciones sociales de vecindad y confianza. Como un planteamiento de buenas intenciones, que no se fundamenta en la idealización pretérita de la ciudad, cabría rescatar las ideas de Robles (2010) e incorporarlas a las políticas urbanas para mantener los mercados como espacios de encuentro e intercambio económico y social, que refuerzan la vida comunitaria en nuestras ciudades.

\section{Bibliografía}

Albet, Abel y Maria Garcia Ramon (2014),"La Barcelona pre- y postolímpica, ¿un modelo para la regeneración urbana actual?”, en Maria Garcia, Ana Ortiz y Maria Prats (eds.), Espacios públicos, género y diversidad, Barcelona: Icaria, pp. 5I-60.

Antigüedad, María (2015),"El desarrollo de la ciudad industrial", en María Antigüedad y Víctor Nieto (eds.), El Siglo xIx: la mirada al pasado y la modernidad, Madrid: Editorial Universitaria Ramón Areces, pp. 143- 177. 
Banco Interamericano de Desarrollo (2007), Los mercados minoristas como motor de desarrollo económico, social y cultural de una ciudad, Nueva York: BID.

Boldrini, Paula y Matilde Malizia (2013),"Procesos de gentrificación y contragentrificación. Los mercados de abasto del norte en el Gran San Miguel de Tucumán", Instituto De Vivienda Del Distrito Federal, 8I, pp. I57-I9I.

Borja, Jordi (1995), Barcelona: un modelo de transformación urbana, 1980-1995, Quito: Programa de Gestión Urbana.

Bourdieu, Pierre (1989), La distinción. Criterio y bases sociales del gusto, Madrid: Taurus.

Cabruja, Adolf (1992),"El planeamiento municipal en urbanismo comercial. El ejemplo de Barcelona", Distribución y Consumo, 2, en línea: <http:// www.mercasa.es/publicaciones/documentacion/pdf_el_planeamiento_municipal_en_urbanismo_comercial_el_ejemplo_de_barcelona $>$ [consulta: agosto de 2015].

Capel, Horacio (2005), El modelo Barcelona: un examen crítico, Barcelona: Ediciones del Serbal.

Delgado, Manuel (2014), "Jerarquización por rango de autenticidad de los espacios de un mercado 'tradicional' en un pueblo de la comarca de Goierri. El cor de las aparences". Bloc de Manuel Delgado, en línea <http:// manueldelgadoruiz.blogspot. $\mathrm{mx} / 20 \mathrm{I2} / 06 /$ jerarquizacion-por-rango-de.html> [consulta: marzo de 2015].

Delgado, Manuel (2007), La ciudad mentirosa. Fraude y miseria del "modelo Barcelona", Madrid: Catarata.

Delgadillo, Víctor (2016), "La disputa por los mercados de La Merced”, Alteridades, 26, pp. 57-69.

Díaz, Ibán (2013), "La gentrificación en la cambiante estructura espacial de la ciudad", Biblio $3 W$, I030, en línea <http://www.ub.edu/geocrit/b3wIO30.htm> [consulta: noviembre de 2015].

Fava, Nadia, Manuel Guàrdia y José Oyòn (2009), "I Mercati di Barcellona: attualità e la loro attualità", Urbanistica, I39, pp. II3-I20.

García, Marisol (2008), "Barcelona: ciudadanos y visitantes”, en Mónica Degen y Marisol García (eds.), La Metaciudad: Barcelona. Transformación de una metrópolis, Barcelona: Anthropos, pp. 97-III.

González, Sara y Waley Paul (2012), “Traditional Retail Markets: The New Gentrification Frontier?”, Antipode, 45, pp. 965-983.

Guàrdia, Manuel, José Oyón y Nadia Fava (2015), “The Barcelona Market System”, en Manuel Guràrdia y Josè Oyón (eds.), Making cities through 
Markets Halls: Europe, 19th and 2oth Centuries, Barcelona: Museu d'Història de Barcelona, pp. 26I-296.

Guàrdia, Manuel (2012),"Mercats i identitat alimentària”, Barcelona Metropolis, 86, en línea <http://lameva.barcelona.cat/bcnmetropolis/dossier/ mercats-i-identitat-alimentaria/ $>$ [consulta: marzo de 2015].

Guàrdia, Manuel, Nadia Fava y José Oyón (2010), "Retailing and proximity in a liveable city: the case of Barcelona public markets system", Ponencia presentada en la Conferencia Internacional de Urbanismo, Viena, mayo, en línea <http://upcommons.upc.edu/handle/2117/75II > [consulta: mayo de 2017].

Guàrdia, Manuel y José Oyón (2007),"Los mercados públicos en la ciudad contemporánea. El caso de Barcelona”, Biblio 3 W, 744, en línea: <http:// www.ub.es/geocrit/b3w-744.htm> [consulta: mayo de 2017].

Harvey, David (1989),"From managerialism to entrepeneurialism: the transformation in urban governance in late capitalism", Geografiska Annaler, 7I, pp. 3-17.

Hernández, Adrián (2014), "Gentrificación comercial y mercados públicos: El Mercado de Santa Caterina, Barcelona”. Working Paper Contested Cities, en línea <http://contested-cities.net/working-papers/20I4/gentrificacion-comercial-y-mercados-publicos-el-mercado-de-santa-Catalina-barcelona/> [consulta: enero de 2015].

Hernández, Adrián (2016), En trasformación... Gentrificación en el Casc Antic de Barcelona, México: Universidad Nacional Autónoma de México.

Hernández, Adrián y Stoyanka Andreeva (2016), ‘¿Mercados, museos o malls? La gentrificación de los mercados municipales en Barcelona y Madrid”, EntreDiversidades, 6, pp. 143-173.

Hiernaux, Daniel (2012), "Los centros históricos: temporalidad, espacialidad y gentrificación”, en Carmen González y Daniel Hiernaux (eds.), Espacio-temporalidad y prácticas sociales en los centros históricos mexicanos, Querétaro: Universidad Autónoma de Querétaro, pp. 13-25.

Instituto de Mercados de Barcelona (2012), The Markets of the Mediterranean, Barcelona: Імв.

Judd, Denis (2003), "El turismo urbano y la geografía de la ciudad", EURE, 87, pp. 5I-62.

Juste, Ángel (1993), "Mercados minoristas tradicionales. La remodelación necesaria”, Distribución y Consumo, II, en línea <http://www.mercasa.es/ 
files/multimedios/1306855II3_DYC_I993_II_IO_26.pdf> [consulta: abril de 2015].

López, Ramón (2007), "Comercio y periferia: el caso de la Región de Madrid", Ciudades, Io, pp. 185-202.

López, Ramón (2002), "La vitalidad del espacio público urbano en riesgo", Distribución y Consumo, 26, en línea <http://www.mercasa.es/files/multimedios/1297616155_DYC_2002_66_25_37.pdf> [consulta: mayo de 2015].

López, Pere (1986), El Centro Histórico: un lugar para el conflicto, Barcelona: Universidad de Barcelona.

Medina, Xavier y Marcelo Álvarez (2009), "El lugar por donde pasa la vida... Los mercados y las demandas urbanas contemporáneas: Barcelona y Buenos Aires", en Xavier Medina et al. (eds.), Alimentación, imaginarios $y$ fronteras culturales. Ensayos en honor a Helen Macbeth, Guadalajara: Universidad de Guadalajara, pp. 183-20I.

Miralles, Enric y Bendeta Tagliabue (2005), Work in progress = estado de las obras, Barcelona: Colegio de Arquitectos de Cataluña.

Montaner, Josep Maria (2012a), "La evolución del Modelo Barcelona (19732004)", en Josep Maria Montaner et al. (eds.), Archivo crítico del Modelo Barcelona, Barcelona: Ayuntamiento de Barcelona-Escuela Técnica Superior de Arquitectura de Barcelona de la Universidad Politécnica de Cataluña, pp. 33-48.

Montaner, Josep Maria (20I2b), "Barcelona, de modelo urbano a marca de ciudad”, en Josep Maria Montaner et. al (eds.), Archivo crítico del Modelo Barcelona, Barcelona: Ayuntamiento de Barcelona-Escuela Técnica Superior de Arquitectura de Barcelona de la Universidad Politécnica de Cataluña, pp. 217-224.

Ogden, Philip y François Schnoebelen (2005), "The Rise of the Small Household: Demographic Change and Household Structure in Paris", Population, Space and Place, II, pp. 25I-268.

Ogden, Philip y Ray Hall (2004), "The second demographic transition, new household forms and the urban population of France during the 1990s", Transactions of the Royal British Society, 29, pp. 88-105.

Pintaudi, Silvana (2006), "Os mercados públicos: metamorfoses de um espaço na história urbana”, Scripta Nova, 218, en línea <http://www.ub.es/ geocrit/sn/sn-2I8-8I.htm $>$ [consulta: abril de 20I6].

Robles, Juan (2010), "Pequeños comerciantes: mediadores urbanos”, Revista Chilena de Antropología Visual, I5, pp. 164-190. (2008),"Comercio urbano en 
espacios metropolitanos", Distribución y Consumo, I9, en línea <http:// www.mercasa.es/files/multimedios/r28640663I_Comercio_urbano_ en_espacios_metropolitanos.pdf > [consulta: agosto de 2015].

Subirats, Joan y Joaquim Rius (2008), Del Xino al Raval: cultura i transformació social a la Barcelona central, Barcelona: Centro de Cultura Contemporánea de Barcelona-Instituto de Gobierno y Políticas Públicas.

Vázquez Montalbán, Manuel (200I), La Boqueria: la catedral de los sentidos. Barcelona, Barcelona: Ajuntament de Barcelona.

Tapada, Teresa y Sonia Arbaci (20II), "Proyectos de regeneración urbana en Barcelona contra la segregación socioespacial (1986-2009): ¿Solución o mito?", Architecture, City and Environment, 17, pp. 187-222.

Watson, Sophie (2009),"The Magic of the Marketplace: Sociality in a Neglected Public Space", Urban Studies, 46, I577-I59I.

RESUMEN CURRICULAR

Adrián Hernández Cordero es licenciado en Geografía Humana por la Universidad Autónoma Metropolitana Iztapalapa. Posee maestría en Estudios Regionales por el Instituto Mora de la Ciudad de México y Doctorado en Geografía por la Universidad Autónoma de Barcelona. Actualmente se desempeña como profesor asociado en la Universidad Autónoma Metropolitana Iztapalapa y es miembro del Sistema Nacional de Investigadores del Consejo Nacional de Ciencia y Tecnología. Su línea de investigación se ubica en la Geografía Urbana, y particularmente en los procesos de gentrificación de las áreas centrales.

Citar como: Hernández Cordero, Adrían (2017), "Los mercados públicos: espacios urbanos en disputa", Iztapalapa. Revista de Ciencias Sociales y Humanidades, núm. 83, año 38, julio-diciembre de 2017, IssN: 2007-9176; pp.165-186. Disponible en <http://revistaiztapalapa.izt.uam.mx/index.php/ izt/issue/archive $>$. 